\title{
molecules
}

ISSN 1420-3049

www.mdpi.com/journal/molecules

Article

\section{Synthesis and Cytotoxicity of Novel 10-Substituted Dihydroartemisinin Derivatives Containing $N$-Arylphenyl-ethenesulfonamide Groups}

\section{Yajing Liu, Zijian Liu, Jiyue Shi, Huimin Chen, Bin Mi, Peng Li and Ping Gong*}

Key Laboratory of Original New Drug Design and Discovery of Ministry of Education, School of Pharmaceutical Engineering, Shenyang Pharmaceutical University, Shenyang 110016, China

* Author to whom correspondence should be addressed; E-Mail: gongpinggp@126.com; Tel./Fax: +86-24-2398-6429.

Received: 4 December 2012; in revised form: 28 December 2012 / Accepted: 31 December 2012 / Published: 4 March 2013

\begin{abstract}
The manuscript describes the synthesis of 10-substituted dihydroartemisinin derivatives containing $N$-aryl phenylethenesulfonamide groups and their in vitro anti-tumor activities against the HT-29, MDA-MB-231, U87MG, H460, A549 and HL-60 cancer cell lines and the normal WI-38 cell line. Most tested compounds showed enhanced cytotoxic activities and good selectivity toward the MDA-MB-231, HT-29 and HL-60 cell lines, with $\mathrm{IC}_{50}$ values in the single-digit $\mu \mathrm{M}$ range as compared with dihydroartemisinin (DHA), and all of them displayed less toxicity towards WI-38 cells. Among them, compounds $3 \mathbf{c}$ and $\mathbf{6 c}$ with trifluoromethoxy groups on the $N$-phenyl ring were found to be most active compounds against the six tested cancer cell lines.
\end{abstract}

Keywords: 10 -substituted dihydroartemisinin derivatives; synthesis; anti-cancer

\section{Introduction}

Artemisinin is a sesquiterpene lactone isolated from the plant Artemesia annua L. Artemisinin and its derivatives, such as dihydroartemisinin (DHA) [1], artemether, arteether, and artesunate [2], are widely used currently as front-line antimalarials [3,4]. Despite the reported neurotoxic and embryotoxic effects in animals occurring at higher doses, application of artemisinins in humans seems to be relatively safe [5]. In addition to their well-known antimalarial activity, artemisinin derivatives possess cytotoxic activity against cancer cells by inducing apoptosis [6], but high concentrations are required [7]. 
Therefore, the synthesis of new, structurally modified derivatives of artemisinin is essential. The high chemical sensitivity of the artemisinin molecule restricts broad derivatization for library synthesis for further clinical development. So far the majority of the artemisinin derivatizations were carried out on the $\mathrm{C}-10$ acetal and to a lesser extent on the $\mathrm{C}-13$ carbon [8]. The observation that dihydroartemisinin $\mathrm{C}-10$ ester, ether or amide derivatives (Figure 1) possess significant antitumor activity prompted previous efforts, both within our group [9,10] and by others [11-13].

Figure 1. Structures of artesiminin derivatives.

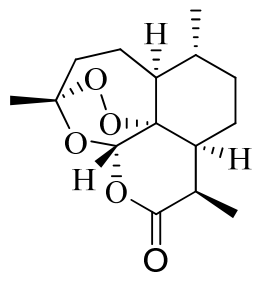

Artesiminin

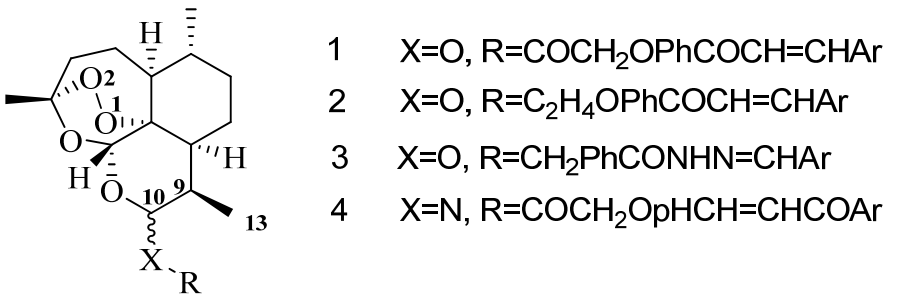

Hybrid drugs are formed by covalently linking two distinct chemical moieties with different biological modes of action with the aim of creating binary therapies with improved biological activity and less susceptible to the development of drug resistance [14,15]. Some $N$-aryl-2-arylethenesulfonamides, a new class of small molecule antitubulin agents, have exhibited potent activity against a wide spectrum of cancer cell lines, especially including some drug-resistant cell lines (e.g., MES-SA, HCT116, MDA-MB, etc.). Among them, ON 24160 (5, Figure 2) was the most promising compound, with significant cytotoxicity against multiple cancer cell lines and a suitable pharmacokinetic profile [16,17]. Therefore, we have now synthesized a short series of dihydroartemisinin derivatives $\mathbf{3 a}-\mathbf{h}$ in which the $\mathrm{C}-10$ hydroxy was covalently linked to the $N$-aryl-2-arylethenesulfonamide moiety with a two-carbon chain (Figure 2). To expand the search for new antitumor compounds, the $N$-methylbenzamide scaffold was next inserted into the two-carbon chain linker to obtain compounds $\mathbf{6 a}$ to $\mathbf{6 j}$ (Figure 2).

Figure 2. Design strategy for target compounds.

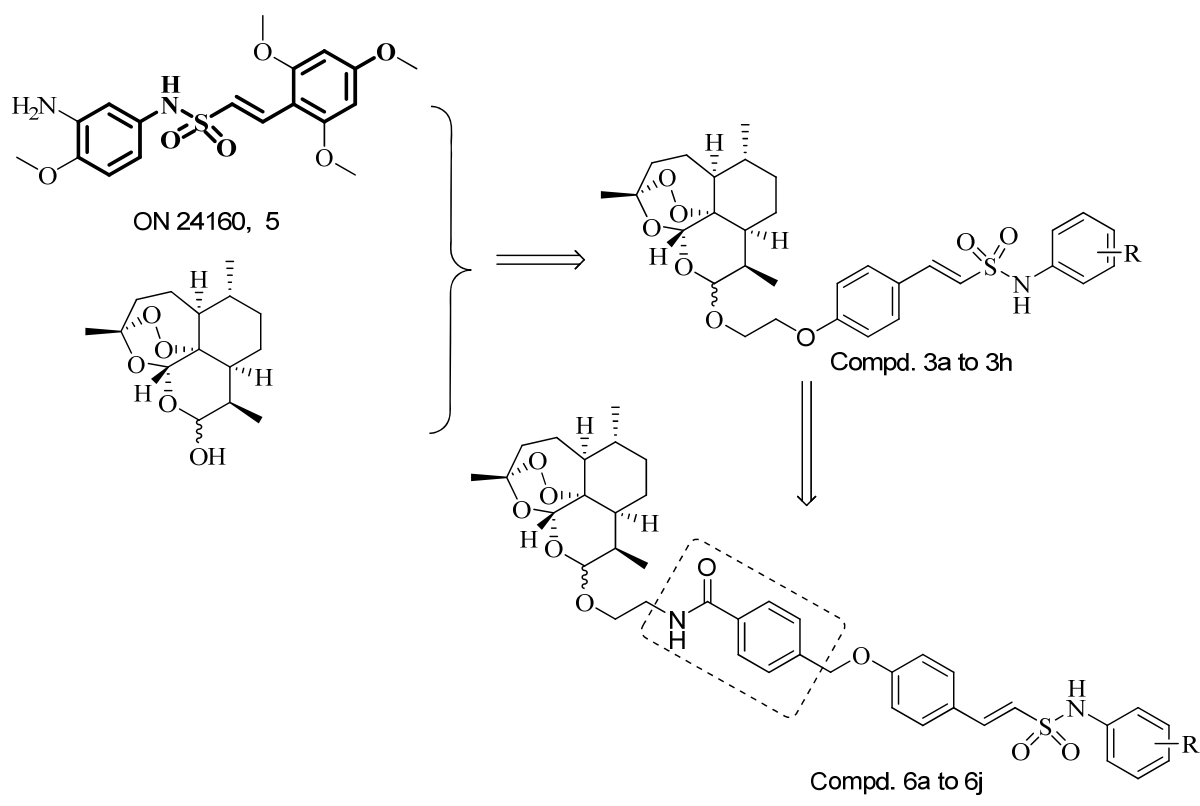


In this study, the synthesis of novel $\mathrm{N}$-aryl phenylethenesulfonamides dihydroartemisinin derivatives (compounds 3a-h and $\mathbf{6 a}-\mathbf{j}$, Figure 2) was reported. Most of them exhibited potent cytotoxic activity against six human cancer cell lines, including the HT-29, MDA-MB-231, U87MG, H460, A549 and HL-60 cell lines.

\section{Results and Discussion}

\subsection{Chemistry}

The syntheses of target compounds $3 \mathbf{a}-\mathbf{h}$ and $\mathbf{6 a}-\mathbf{j}$ are outlined in Scheme 1. Reduction of artemisinin (1) with $\mathrm{NaBH}_{4}$ gave dihydroartemisinin (2) as mixture of $10 \alpha$ and $10 \beta$ epimers which reacted with 2-bromoethanol directly using the Lewis acid $\mathrm{BF} 3 \cdot \mathrm{Et}_{2} \mathrm{O}$ as catalyst to give 10-bromoethoxydihydroartemisinin (3) [18]. In our previous report, the stereochemistry of compound $\mathbf{3}$ had already been determined as $10 \beta$ by the ${ }^{1} \mathrm{H}-\mathrm{NMR}$ coupling constant $(J=3.4 \mathrm{~Hz})$ between $9-\mathrm{H}$ and $10-\mathrm{H}$ and the chemical shift of 10-H (4.77 ppm) [9]. Subsequently, the target compounds 3a-h were prepared in reasonable yield by potassium iodide-catalyzed substitution of bromo compound 3 with $\mathrm{N}$-aryl-4hydroxyphenylethane-sulfonamides $\mathbf{1 0}$ in the presence of potassium carbonate.

Scheme 1. The synthetic route to the target compounds.
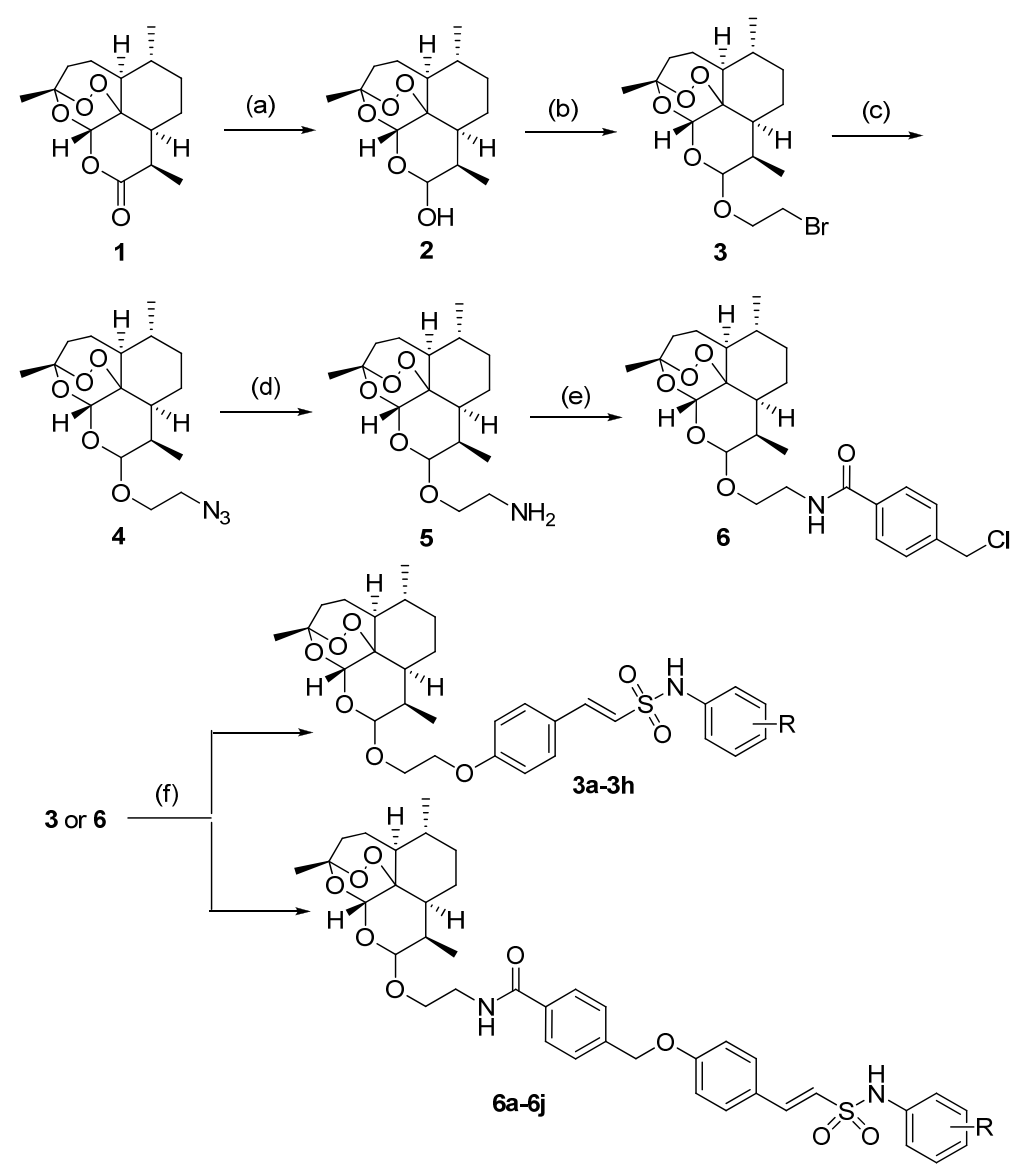

Reagents and conditions: (a) $\mathrm{NaBH}_{4}$, methanol, $0{ }^{\circ} \mathrm{C}, 2 \mathrm{~h}$; (b) 2-bromoethanol, $\mathrm{BF}_{3} \cdot \mathrm{Et}_{2} \mathrm{O}$, dichloromethane, $0{ }^{\circ} \mathrm{C}, 1 \mathrm{~h}$; (c) $\mathrm{NaN}_{3}$, NaI, DMF, $60{ }^{\circ} \mathrm{C}, 7 \mathrm{~h}$; (d) (1) $\mathrm{PPh}_{3}$, THF, $60{ }^{\circ} \mathrm{C}, 2 \mathrm{~h}$; (2) $\mathrm{H}_{2} \mathrm{O}$, $70{ }^{\circ} \mathrm{C}, 1 \mathrm{~h}$; (e) 4-(chloromethyl)benzoyl chloride, DMF, r.t., $1 \mathrm{~h}$; (f) intermediate 10, $\mathrm{K}_{2} \mathrm{CO}_{3}$, $\mathrm{KI}$, acetone, $50^{\circ} \mathrm{C}$ to reflux, 2 to $7 \mathrm{~h}$. 
Regarding the side chain, $N$-aryl-2-arylethenesulfonamide derivatives $\mathbf{1 0}$ were prepared from ethyl bromoacetate according to Scheme 2. Reaction of ethyl bromoacetate with $\mathrm{Na}_{2} \mathrm{SO}_{3}$ afforded sodium 2-ethoxy-2-oxoethanesulfonate (7), which was converted to the sulfonyl chloride $\mathbf{8}$ via chlorination using $\mathrm{POCl}_{3}$. Then condensation of compound $\mathbf{8}$ with the corresponding substituted anilines in toluene gave the ethyl 2-( $N$-arylsulfamonyl)acetates $\mathbf{9}$. Finally, reaction of compounds 9 with 4-hydroxybenzaldehyde afforded the desired side chains $\mathbf{1 0}$ in high yield.

Scheme 2. The synthetic route to the side chain $\mathbf{1 0}$.
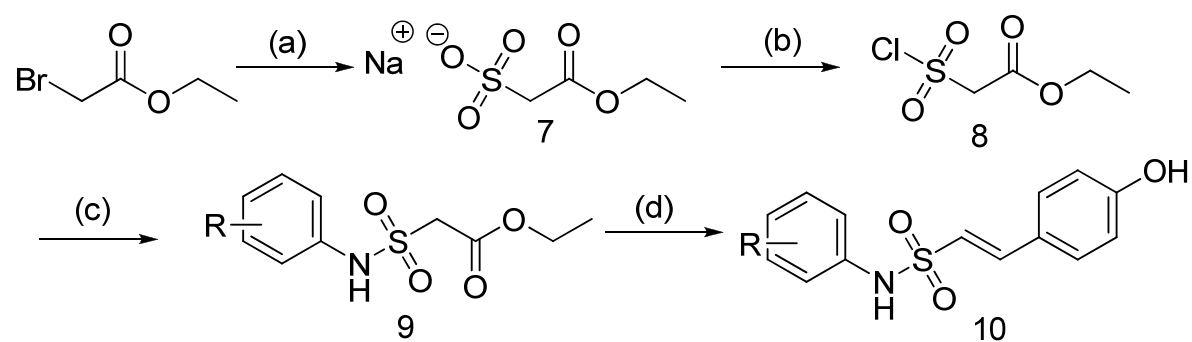

Reagents and conditions: (a) $\mathrm{Na}_{2} \mathrm{SO}_{3}$, ethanol, $\mathrm{H}_{2} \mathrm{O}, 50{ }^{\circ} \mathrm{C}, 1 \mathrm{~h}$; (b) $\mathrm{POCl}_{3}, 80{ }^{\circ} \mathrm{C}, 2 \mathrm{~h}$; (c) substituted aniline, triethylamine, toluene, r.t., $0.5 \mathrm{~h}$; (d) 4-hydroxybenzaldehyde, pyridine, ammonium acetate, toluene, $110^{\circ} \mathrm{C}, 8 \mathrm{~h}$.

The target compounds $\mathbf{6 a}-\mathbf{j}$ with the extend side chain were prepared from intermediate $\mathbf{3}$. Firstly, treatment of 3 with sodium azide under sodium iodide catalysis in DMF according to a modified Haynes' method [19] gave 10 $\beta$-azidoethoxydihydroartemisinin (4). The Staudinger reduction was used in the transformation of azido compound 4 to $10 \beta$-aminoethoxydihydroartemisinin (5). Acylation of the amino group of $\mathbf{5}$ yielded $10 \beta$-arylamidoethoxydihydroartemisinin (6). Compounds $\mathbf{6 a}-\mathbf{j}$ were prepared using a procedure similar to that used to synthesize compounds $\mathbf{3 a}-\mathbf{h}$.

The formation of the four key intermediates 3-6 was confirmed by ${ }^{1} \mathrm{H}-\mathrm{NMR}$ and LC-MS data, The formation of the title compounds $\mathbf{3 a}-\mathbf{h}$ and $\mathbf{6 a}-\mathbf{j}$ was evidenced by their ${ }^{1} \mathrm{H}-\mathrm{NMR}$, IR and LC-MS spectra, explained in the Experimental section.

\subsection{Biological Activity}

The cytotoxic activities of target compounds were evaluated against HT-29 (human colon cancer), MDA-MB-231 (human breast cancer), U87MG (human glioblastoma), H460 (human lung cancer), A549 (non-small-cell lung adenocarcinoma), HL-60 (human leukemic) cancer cell lines and one normal cell line WI-38 (human fetal lung fibroblasts) together with references DHA and cisplatin by a MTT assay. The results, expressed as averaged $\mathrm{IC}_{50}$ values from at least three independent experiments, are summarized in Table 1.

As illustrated in Table 1, all of the target compounds showed moderate to excellent cytotoxic activities against the different cancer cell lines in the single-digit $\mu \mathrm{M}$ range, and displayed less toxicity against normal WI-38 cells. In general, most of the compounds displayed significant selectivity toward MDA-MB-231, HT-29 and HL-60 cancer cells. It was worth noting that compounds $\mathbf{3 c}$ and $6 \mathrm{c}$ exhibited excellent anti-tumor activities against MDA-MB-231, HT-29 and HL-60 cells with $\mathrm{IC}_{50}$ values in the tenths of a digit $\mathrm{nM}$ range. Moreover, the selectivity index $\left(\mathrm{IC}_{50}\right.$ normal cell/ $\mathrm{IC}_{50}$ cancer cell) of compound 3c for HL-60 was 750, which demonstrated that the tumor cells were more sensitive than the normal cells. 
Table 1. Structures and cytotoxicity of compounds against HT-29, MDA-MB-231, U87MG, H460, A549, HL-60 and WI38 cell lines.

\begin{tabular}{|c|c|c|c|c|c|c|c|c|}
\hline \multirow{2}{*}{ Compd. } & \multirow{2}{*}{$\mathbf{R}$} & \multicolumn{7}{|c|}{$\mathrm{IC}_{50}(\mu \mathrm{M})^{\mathrm{a}}$} \\
\hline & & MDA & HT29 & U87MG & H460 & A549 & HL-60 & WI38 \\
\hline $3 \mathbf{a}$ & $\mathrm{H}$ & 2.00 & 0.68 & 3.97 & 5.38 & 2.16 & 1.25 & 16.75 \\
\hline $3 \mathbf{b}$ & 3-chloro & 1.61 & 0.78 & 3.51 & 7.32 & 4.48 & 0.75 & 23.88 \\
\hline $3 \mathbf{c}$ & 4-trifluoromethoxy & 0.39 & 0.20 & 1.59 & 0.97 & 2.11 & 0.05 & 37.47 \\
\hline 3d & 2-fluoro-5-methyl & 1.27 & 1.78 & 5.71 & 4.29 & 3.64 & 0.84 & 20.53 \\
\hline $3 \mathbf{e}$ & 2-methyl & 1.64 & 0.86 & 2.73 & 1.58 & 7.32 & 2.37 & 16.44 \\
\hline $3 f$ & 4-chloro & 1.04 & 0.42 & 0.79 & 1.41 & 3.52 & 0.08 & 19.88 \\
\hline $3 g$ & 2-chloro & 0.93 & 0.55 & 1.78 & 2.53 & 3.05 & 0.17 & 16.33 \\
\hline $3 \mathbf{h}$ & 2,6-dichloro & 1.07 & 0.49 & 2.51 & 1.28 & 4.33 & 0.14 & 20.74 \\
\hline $6 c$ & 4-trifluoromethoxy & 0.49 & 0.29 & 3.71 & 2.70 & 1.57 & 0.09 & 28.17 \\
\hline $6 \mathbf{b}$ & 3-chloro & 2.23 & 1.11 & 4.52 & 2.79 & 2.86 & 1.81 & 35.76 \\
\hline $6 \mathbf{a}$ & $\mathrm{H}$ & 2.26 & 0.98 & 6.47 & 5.28 & 3.21 & 2.41 & 20.04 \\
\hline 6d & 2-fluoro-5-methyl & 1.33 & 1.82 & 17.24 & 10.88 & 9.72 & 1.30 & 19.28 \\
\hline $6 e$ & 2-methyl & 2.10 & 2.09 & 3.65 & 1.92 & 5.47 & 3.21 & 16.39 \\
\hline $6 f$ & 4-chloro & 2.38 & 0.92 & 1.59 & 1.77 & 5.72 & 1.33 & 24.70 \\
\hline $6 \mathbf{i}$ & 3-methoxy & 8.89 & 8.95 & $>100$ & 16.32 & 11.34 & 8.53 & 19.21 \\
\hline $6 \mathbf{j}$ & 4-fluoro-3-trifluoromethyl & 1.05 & 0.38 & 3.27 & 5.31 & 2.78 & 1.27 & 30.37 \\
\hline $6 \mathrm{~g}$ & 2-chloro & 0.72 & 0.45 & 2.69 & 0.89 & 5.31 & 0.27 & 27.20 \\
\hline $\mathbf{6 h}$ & 2,6-dichloro & 0.88 & 0.44 & 3.12 & 1.21 & 2.34 & 0.18 & 23.5 \\
\hline DHA $^{\mathrm{b}}$ & & 9.80 & 5.60 & 15.82 & 12.37 & 10.14 & 5.29 & $>100$ \\
\hline Cisplatin $^{\mathrm{b}}$ & & 6.82 & 10.31 & 8.21 & 7.55 & 4.31 & 9.28 & 51.22 \\
\hline
\end{tabular}

NA: compound showing $\mathrm{IC}_{50}$ value $>200 \mu \mathrm{M}$. ND: not determined. ${ }^{\mathrm{a}} \mathrm{IC}_{50}$ : concentration of the compound $(\mu \mathrm{M})$ producing $50 \%$ cell growth inhibition after $72 \mathrm{~h}$ of drug exposure, as determined by the MTT assay. Each experiment was run at least three times, and the results are presented as average values \pm standard deviation.

${ }^{\mathrm{b}}$ Used as a positive control.

Analysis of Table 1 clearly reveals that the cytotoxicities of benzamide derivatives $\mathbf{6 a}-\mathbf{j}$ were lower than those of the corresponding compounds $\mathbf{3 a}-\mathbf{h}$. For example, the activity of compound $\mathbf{3 c}$ was 2-, 3and 2-fold higher than that of benzamide analog $6 \mathbf{c}$ against U87MG, H460 and HL-60, respectively. In addition, it is worth mentioning that different biological properties were observed when a variety of groups were introduced into the $N$-phenyl moieties. The activities of compounds $3 \mathbf{b}, \mathbf{3 d}, \mathbf{3 f}-\mathbf{h}, \mathbf{6 b}, \mathbf{6 d}$ and $\mathbf{6 f}-\mathbf{h}$, with the electron-withdrawing halide atoms on the $N$-phenyl moiety, were superior to those with electron-donating groups such as methoxy, or methyl groups or no substitutents $(\mathbf{6 i}, \mathbf{3 e}, \mathbf{6 e}, \mathbf{3 a}$ and 6a). In the first series of compounds $(\mathbf{3 a}-\mathbf{h})$, the 4-chloro derivative (3f) was superior to the fluoro-substituted (3d), disubstituted (3h) or compounds substituted at other positions (3b,g). Nevertheless, the 2-chloro and 2,6-dichloro derivatives 6g,h were better than others in the second series 
of compounds $(\mathbf{6 a}-\mathbf{j})$. Excitingly, the compounds with a trifluoromethoxy group at the 4-position of the $N$-phenyl exhibited exceptionally high potency in two series of compounds, as exemplified by compounds $3 \mathbf{c}$ and $\mathbf{6 c}$.

\section{Experimental}

\subsection{General}

Melting points were measured with a Büchi Melting Point B-540 apparatus (Büchi Labortechnik, Flawil, Switzerland) and are uncorrected. Mass spectra (MS) were taken in ESI mode on Agilent 1100 LC-MS (Agilent, Palo Alto, CA, USA). ${ }^{1} \mathrm{H}-\mathrm{NMR}$ spectra were performed using Bruker $300 \mathrm{MHz}$ spectrometers (Bruker Bioscience, Billerica, MA, USA) with TMS as an internal standard. IR spectra (KBr disks) were recorded with a Bruker IFS 55 instrument (Bruker). Elemental analysis was determined on a Carlo-Erba 1106 Elemental analysis instrument (Carlo Erba, Milan, Italy). Unless otherwise noted, all the materials were obtained from commercially available sources and were used without further purification.

Preparation of Dihydroartemisinin (2). $\mathrm{NaBH}_{4}(12 \mathrm{~g}, 0.32 \mathrm{~mol})$ was added slowly to a stirred solution of artemisinin $(30 \mathrm{~g}, 0.11 \mathrm{~mol})$ in methanol $(300 \mathrm{~mL})$ at $-5 \sim 0{ }^{\circ} \mathrm{C}$. The reaction mixture was stirred at $0{ }^{\circ} \mathrm{C}$ for $2 \mathrm{~h}$, adjusted to $\mathrm{pH} 6$ to 7 with acetic acid, and then concentrated under reduced pressure. The residue was poured into water $(400 \mathrm{~mL})$, and the solid product formed was collected by filtration, washed with water, and dried to yield compound 2 (25 g, 84\%). m.p.: $145-148{ }^{\circ} \mathrm{C}$; MS (ESI, m/z): $283.3(\mathrm{M}-\mathrm{H})^{-}$.

Preparation of 2-(10ß-Dihydroartemisinoxy)ethyl Bromide (3). $\mathrm{BF}_{3} \cdot \mathrm{Et}_{2} \mathrm{O}(16 \mathrm{~mL})$ was added to a solution of dihydroartemisinin $2(20 \mathrm{~g}, 70 \mathrm{mmol})$ and 2-bromoethanol $(13 \mathrm{~g}, 0.11 \mathrm{~mol})$ in $\mathrm{CH}_{2} \mathrm{Cl}_{2}(100 \mathrm{~mL})$ below $0{ }^{\circ} \mathrm{C}$. The mixture was stirred at room temperature until the reaction completed, and then was washed with saturated $\mathrm{NaHCO}_{3}$ solution, water and saturated $\mathrm{NaCl}$ solution. The organic layer was dried and concentrated. The residue was recrystallized from petroleum ether to give compound 3 (13 g, 46\%) as white crystals. m.p.: $155-158{ }^{\circ} \mathrm{C}$; MS (ESI, $\left.m / z\right): 413.2(\mathrm{M}+\mathrm{Na})^{+} ;{ }^{1} \mathrm{H}-\mathrm{NMR}\left(300 \mathrm{MHz}, \mathrm{DMSO}-d_{6}\right) \delta$ : $5.43(\mathrm{~s}, 1 \mathrm{H}), 4.77(\mathrm{~d}, J=3.4 \mathrm{~Hz}, 1 \mathrm{H}), 3.94(\mathrm{td}, J=9.3,4.1 \mathrm{~Hz}, 1 \mathrm{H}), 3.78(\mathrm{~m}, 3 \mathrm{H}), 2.47(\mathrm{~m}, 1 \mathrm{H}), 2.25(\mathrm{~m}$, $1 \mathrm{H}), 2.05(\mathrm{~m}, 1 \mathrm{H}), 1.89-1.75(\mathrm{~m}, 2 \mathrm{H}), 1.61(\mathrm{~m}, 2 \mathrm{H}), 1.44-1.31(\mathrm{~m}, 3 \mathrm{H}), 1.29(\mathrm{~s}, 3 \mathrm{H}), 1.22-1.06(\mathrm{~m}, 2 \mathrm{H})$, $0.90(\mathrm{~d}, J=6.5 \mathrm{~Hz}, 3 \mathrm{H}), 0.87(\mathrm{~d}, J=7.5 \mathrm{~Hz}, 3 \mathrm{H})$.

Preparation of 2-(10ß-Dihydroartemisinoxy)ethyl Azide (4). $\mathrm{NaN}_{3}(4.0 \mathrm{~g}, 60 \mathrm{mmol})$ was added to a stirred solution of compound $\mathbf{3}(8.0 \mathrm{~g}, 21 \mathrm{mmol})$ and sodium iodide $(0.15 \mathrm{~g}, 1 \mathrm{mmol})$ in DMF $(60 \mathrm{~mL})$. The reaction mixture was heated to $60{ }^{\circ} \mathrm{C}$ for $3-5 \mathrm{~h}$. The mixture was poured into ice water, stirred for $1 \mathrm{~h}$ and separated by filtration to give white compound 4 (7.1 g, 98\%). m.p.: 86-88 ${ }^{\circ} \mathrm{C}$; MS (ESI, $\left.m / z\right)$ : $376.2(\mathrm{M}+\mathrm{Na})^{+} ;{ }^{1} \mathrm{H}-\mathrm{NMR}\left(300 \mathrm{MHz}, \mathrm{DMSO}-d_{6}\right) \delta: 5.39(\mathrm{~s}, 1 \mathrm{H}), 4.76(\mathrm{~d}, J=3.3 \mathrm{~Hz}, 1 \mathrm{H}), 3.91(\mathrm{~m}, 1 \mathrm{H})$, $3.56(\mathrm{~m}, 3 \mathrm{H}), 2.47(\mathrm{~m}, 1 \mathrm{H}), 2.25(\mathrm{~m}, 1 \mathrm{H}), 2.06(\mathrm{~m}, 1 \mathrm{H}), 1.87(\mathrm{~m}, 4 \mathrm{H}), 1.45(\mathrm{~m}, 3 \mathrm{H}), 1.29(\mathrm{~s}, 3 \mathrm{H})$, $1.14(\mathrm{~m}, 2 \mathrm{H}), 0.90(\mathrm{~d}, J=3.8 \mathrm{~Hz}, 3 \mathrm{H}), 0.88$ (d, $J=4.9 \mathrm{~Hz}, 3 \mathrm{H})$.

Preparation of 2-(10ß-Dihydroartemisinoxy)ethylamine (5). A $100 \mathrm{~mL}$ round-bottomed flask was charged with compound $4(6.0 \mathrm{~g}, 17 \mathrm{mmol})$ and THF $(60 \mathrm{~mL})$. To this solution, triphenylphosphine $(7.2 \mathrm{~g}$, $27 \mathrm{mmol}$ ) was added slowly, and the reaction mixture was stirred for $2 \mathrm{~h}$ at $60{ }^{\circ} \mathrm{C}$. Several drops of water 
$(1.0 \mathrm{~mL}, 56 \mathrm{mmol})$ were added, and the resulting suspension was stirred for $6 \mathrm{~h}$. The mixture was concentrated under reduced pressure. The crude mixture was purified by flash column chromatography (silica gel, dichloromethane/methanol, 200:1) to afford the desired compound 5 (4.1 g, 74\%) as yellow oil. MS (ESI, $m / z): 328.1(\mathrm{M}+\mathrm{H}){ }^{+} ;{ }^{1} \mathrm{H}-\mathrm{NMR}\left(300 \mathrm{MHz}, \mathrm{DMSO}-d_{6}\right) \delta: 5.34(\mathrm{~s}, 1 \mathrm{H}), 4.69$ (d, $J=3.4 \mathrm{~Hz}$, $1 \mathrm{H}), 3.71(\mathrm{~m}, 1 \mathrm{H}), 3.30(\mathrm{dt}, J=9.8,5.7 \mathrm{~Hz}, 1 \mathrm{H}), 2.73(\mathrm{~m}, 2 \mathrm{H}), 2.47(\mathrm{~m}, 1 \mathrm{H}), 2.25(\mathrm{~m}, 1 \mathrm{H}), 2.07(\mathrm{~m}, 1 \mathrm{H})$, $1.86(\mathrm{~m}, 2 \mathrm{H}), 1.78(\mathrm{~m}, 2 \mathrm{H}), 1.63(\mathrm{~m}, 3 \mathrm{H}), 1.29(\mathrm{~s}, 3 \mathrm{H}), 1.21-1.07(\mathrm{~m}, 2 \mathrm{H}), 0.89(\mathrm{~d}, J=6.3 \mathrm{~Hz}, 3 \mathrm{H})$, $0.85(\mathrm{~d}, J=7.4 \mathrm{~Hz}, 3 \mathrm{H})$.

Preparation of 4-(Chloromethyl)-N-2-(10 -dihydroartemisinoxy)ethyl Benzamide (6). A solution of compound $5(4.0 \mathrm{~g}, 12 \mathrm{mmol})$ in DMF $(20 \mathrm{~mL})$ was cooled below $0{ }^{\circ} \mathrm{C}$ and 4 -(chloromethyl)benzoyl chloride (2.3 g, $12 \mathrm{mmol}$ ) was added dropwise. The mixture was stirred at room temperature for $1 \mathrm{~h}$, and then poured into water. The white precipitate was filtered, washed with ethanol, and dried to obtain 6 (5.1 g, 87\%). m.p.: $105-108{ }^{\circ} \mathrm{C}$; MS (ESI, $\left.m / z\right)$ : $480.9(\mathrm{M}+\mathrm{H}){ }^{+} ;{ }^{1} \mathrm{H}-\mathrm{NMR}$ (300 MHz, DMSO- $\left.d_{6}\right) \delta: 7.93$ $(\mathrm{d}, J=7.2 \mathrm{~Hz}, 2 \mathrm{H}), 7.51(\mathrm{~d}, J=7.2 \mathrm{~Hz}, 2 \mathrm{H}), 5.38(\mathrm{~s}, 1 \mathrm{H}), 4.71(\mathrm{~d}, J=3.4 \mathrm{~Hz}, 1 \mathrm{H}), 4.54(\mathrm{~s}, 2 \mathrm{H}), 3.73(\mathrm{~m}$, $1 \mathrm{H}), 3.32(\mathrm{dt}, J=9.8,5.7 \mathrm{~Hz}, 1 \mathrm{H}), 2.75(\mathrm{~m}, 2 \mathrm{H}), 2.49(\mathrm{~m}, 1 \mathrm{H}), 2.28(\mathrm{~m}, 1 \mathrm{H}), 2.11(\mathrm{~m}, 1 \mathrm{H}), 1.89(\mathrm{~m}, 2 \mathrm{H})$, $1.80(\mathrm{~m}, 2 \mathrm{H}), 1.65(\mathrm{~m}, 3 \mathrm{H}), 1.31(\mathrm{~s}, 3 \mathrm{H}), 1.24(\mathrm{~m}, 2 \mathrm{H}), 0.92(\mathrm{~d}, J=6.4 \mathrm{~Hz}, 3 \mathrm{H}), 0.87(\mathrm{~d}, J=7.4 \mathrm{~Hz}, 3 \mathrm{H})$.

Preparation of Sodium 2-Ethoxy-2-oxoethanesulfonate (7). $\mathrm{Na}_{2} \mathrm{SO}_{3}$ (15 g, $0.12 \mathrm{~mol}$ ) was dissolved in water $(50 \mathrm{~mL})$ and a solution of ethyl bromoacetate $(20 \mathrm{~g}, 0.12 \mathrm{~mol})$ in ethanol $(25 \mathrm{~mL})$ was added dropwise at $5-10{ }^{\circ} \mathrm{C}$. The reaction mixture was heated to $50{ }^{\circ} \mathrm{C}$ for $1 \mathrm{~h}$. After then, the solution was evaporated until dryness. Acetic acid $(200 \mathrm{~mL})$ and ethyl acetate $(100 \mathrm{~mL})$ were added to the residue, and the mixture was heated to $100{ }^{\circ} \mathrm{C}$ for $1 \mathrm{~h}$. The hot mixture was filtered, and another $1,000 \mathrm{~mL}$ ethyl acetate was poured into the filtrate. The white crystals were filtered, washed with ethyl acetate, and dried to yield white solid 7 (23 g, 99\%). m.p.: $158^{\circ} \mathrm{C}$ (dec.); MS (ESI, $\left.m / z\right): 190.2(\mathrm{M}+\mathrm{Na})^{+}$.

Preparation of Ethyl 2-(Chlorosulfonyl)acetate (8) A mixture of compound 7 (10 g, $0.053 \mathrm{~mol})$ and $\mathrm{POCl}_{3}(100 \mathrm{~mL}, 1.1 \mathrm{~mol})$ was stirred at $80{ }^{\circ} \mathrm{C}$ for $2 \mathrm{~h}$ and then cooled to room temperature. The solvent was removed under vacuum, $100 \mathrm{~mL}$ of toluene was added, and stirred for $10 \mathrm{~min}$. The reaction solution was filtered, and the solvent was evaporated under reduced pressure to obtain $\mathbf{8}(9.0 \mathrm{~g}, 92 \%)$ as a red oil.

\subsection{General Procedure for the Preparation of Ethyl 2-(N-Arylsulfamoyl)acetate (9)}

A solution of $8(8.0 \mathrm{~g}, 0.043 \mathrm{~mol})$ in toluene $(100 \mathrm{~mL})$ was cooled to $-5 \sim 0{ }^{\circ} \mathrm{C}$, a mixture of substituted aniline $(0.086 \mathrm{~mol})$, triethylamine $(0.065 \mathrm{~mol})$ in toluene $(50 \mathrm{~mL})$ was added dropwise. The reaction mixture was stirred at room temperature for $0.5-1 \mathrm{~h}$, and then washed with water, $5 \% \mathrm{HCl}$, saturated $\mathrm{NaHCO}_{3}$ solution, saturated $\mathrm{NaCl}$ solution and water. The organic phase was dried with $\mathrm{Na}_{2} \mathrm{SO}_{4}$ and evaporated to yield 9 as a brown oil.

\subsection{General Procedure for the Preparation of Ethyl 2-(4-Hydroxyphenyl)-N-arylethenesulfonamides 10}

A mixture of compound $9(0.02 \mathrm{~mol}), 4$-hydroxybenzaldehyde $(5.0 \mathrm{~g}, 0.04 \mathrm{~mol})$, pyridine $(0.40 \mathrm{~mL}$, $5.0 \mathrm{mmol})$, ammonium acetate $(0.40 \mathrm{~g}, 5.0 \mathrm{mmol})$ and toluene $(100 \mathrm{~mL})$ was stirred at $110^{\circ} \mathrm{C}$ for $8-10 \mathrm{~h}$ and then cooled to room temperature. The toluene phase was washed with $5 \% \mathrm{HCl}$, saturated $\mathrm{NaHCO}_{3}$ solution and water, dried with $\mathrm{Na}_{2} \mathrm{SO}_{4}$ to obtain $\mathbf{1 0}$ as a brick red oil. 


\subsection{General Procedure for the Preparation of Target Compounds $\mathbf{3 a}-\mathbf{h}$}

A mixture of compound 3 (10 g, $0.026 \mathrm{~mol}), 10$ (0.026 mol), $\mathrm{K}_{2} \mathrm{CO}_{3}(5.4 \mathrm{~g}, 0.039 \mathrm{~mol}), \mathrm{KI}(0.40 \mathrm{~g}$, $2.6 \mathrm{mmol})$ and acetone $(100 \mathrm{~mL})$ was stirred at $50{ }^{\circ} \mathrm{C}$ for $2-3 \mathrm{~h}$. The reaction solvent was evaporated and the residue was purified by column chromatography (silica-gel, $1 \%-5 \%$ petroleum ether/ethyl acetate) to afford pure compounds $\mathbf{3 a}-\mathbf{h}$.

\subsection{General Procedure for the Preparation of Target Compounds $\mathbf{6 a}-\mathbf{j}$}

A mixture of compound $10(0.024 \mathrm{~mol}), \mathrm{K}_{2} \mathrm{CO}_{3}(4.2 \mathrm{~g}, 0.03 \mathrm{~mol})$ and acetone $(100 \mathrm{~mL})$ was stirred at room temperature for $10 \mathrm{~min}$, and then compound 6 (9.6 g, $0.02 \mathrm{~mol})$ and $\mathrm{KI}(0.4 \mathrm{~g}, 2.6 \mathrm{mmol})$ was added while the reaction refluxed for 7-9 h. The acetone was removed under vacuum, and $\mathrm{CH}_{2} \mathrm{Cl}_{2}(100 \mathrm{~mL})$ was poured into the residue. The solution was washed with water, dried with $\mathrm{Na}_{2} \mathrm{SO}_{4}$. The solvent was evaporated and the residue was purified by column chromatography (silica-gel, $1 \%-5 \%$ petroleum ether/ethyl acetate) to afford pure compounds $\mathbf{6 a}-\mathbf{j}$.

(E)-2-(4-(2-(10ß-Dihydroartemisinoxy)ethoxy)phenyl)-N-phenylethenesulfonamide (3a). Light yellow solid (38\% yield); m.p.: 136-138 ${ }^{\circ} \mathrm{C}$; MS (ESI) $m / z$ : $584.2(\mathrm{M}-\mathrm{H})^{-}$; IR (KBr) cm ${ }^{-1}$ : 3422.1, 2923.1, 1603.8, 1514.4, 1343.4, 1147.5, 1027.3, 983.5, 696.9, 597.1; ${ }^{1} \mathrm{H}-\mathrm{NMR}\left(300 \mathrm{MHz}, \mathrm{DMSO}-d_{6}\right) \delta$ : $7.54(\mathrm{~d}$, $J=7.2 \mathrm{~Hz}, 2 \mathrm{H}), 7.35(\mathrm{~m}, 5 \mathrm{H}), 7.15(\mathrm{~d}, J=15.2 \mathrm{~Hz}, 1 \mathrm{H}), 7.05(\mathrm{~d}, J=15.2 \mathrm{~Hz}, 1 \mathrm{H}), 6.79(\mathrm{~d}, J=7.5 \mathrm{~Hz}$, 2H), $5.22(\mathrm{~s}, 1 \mathrm{H}), 4.60(\mathrm{~s}, 1 \mathrm{H}), 3.80(\mathrm{~m}, 2 \mathrm{H}), 3.70(\mathrm{~m}, 2 \mathrm{H}), 3.28(\mathrm{~m}, 1 \mathrm{H}), 2.83(\mathrm{~m}, 2 \mathrm{H}), 2.49(\mathrm{~m}, 1 \mathrm{H})$, $2.33(\mathrm{~m}, 1 \mathrm{H}), 2.16(\mathrm{~m}, 1 \mathrm{H}), 1.99(\mathrm{~m}, 1 \mathrm{H}), 1.76(\mathrm{~m}, 1 \mathrm{H}), 1.47(\mathrm{~m}, 1 \mathrm{H}), 1.28(\mathrm{~m}, 2 \mathrm{H}), 1.26(\mathrm{~s}, 3 \mathrm{H}), 1.08$ $(\mathrm{s}, 1 \mathrm{H}), 0.88(\mathrm{~d}, J=4.8 \mathrm{~Hz}, 3 \mathrm{H}), 0.75(\mathrm{~d}, J=7.1 \mathrm{~Hz}, 3 \mathrm{H})$. Anal. Calcd. for $\mathrm{C}_{31} \mathrm{H}_{39} \mathrm{NO}_{8} \mathrm{~S}: \mathrm{C}$ 63.57, H 6.71, N 2.39. Found: C 63.52, H 6.50, N 2.41.

(E)-2-(4-(2-(10ß-Dihydroartemisinoxy)ethoxy)phenyl)-N-(3-chlorophenyl)ethenesulfonamide (3b). Light yellow solid (44\% yield); m.p.: 137-138 ${ }^{\circ} \mathrm{C}$; MS (ESI) $m / z: 618.0(\mathrm{M}-\mathrm{H})^{-}$; IR (KBr) cm ${ }^{-1}: 3477.3$, 2923.4, 1603.4, 1514.3, 1343.9, 1148.9, 1027.6, 983.4, 788.6, 597.7; ${ }^{1} \mathrm{H}-\mathrm{NMR}$ (300 MHz, DMSO- $d_{6}$ ) $\delta 10.12(\mathrm{br}, 1 \mathrm{H}), 7.58(\mathrm{~d}, J=8.6 \mathrm{~Hz}, 2 \mathrm{H}), 7.45(\mathrm{~m}, 4 \mathrm{H}), 7.19(\mathrm{~d}, J=15.3 \mathrm{~Hz}, 1 \mathrm{H}), 7.08(\mathrm{~d}, J=15.3 \mathrm{~Hz}$, $1 \mathrm{H}), 6.80(\mathrm{~d}, J=8.6 \mathrm{~Hz}, 2 \mathrm{H}), 5.22(\mathrm{~s}, 1 \mathrm{H}), 4.60(\mathrm{~d}, J=3.1 \mathrm{~Hz}, 1 \mathrm{H}), 3.83(\mathrm{~m}, 2 \mathrm{H}), 3.71(\mathrm{~m}, 2 \mathrm{H}), 3.04$ $(\mathrm{s}, 1 \mathrm{H}), 2.32(\mathrm{~m}, 2 \mathrm{H}), 2.13(\mathrm{~d}, J=10.0 \mathrm{~Hz}, 1 \mathrm{H}), 2.00(\mathrm{t}, J=13.9 \mathrm{~Hz}, 1 \mathrm{H}), 1.76(\mathrm{~m}, 1 \mathrm{H}), 1.45(\mathrm{~m}, 2 \mathrm{H})$, $1.25(\mathrm{~d}, J=8.7 \mathrm{~Hz}, 5 \mathrm{H}), 1.11$ (d, $J=18.8 \mathrm{~Hz}, 2 \mathrm{H}), 0.88$ (d, $J=6.2 \mathrm{~Hz}, 3 \mathrm{H}), 0.72(\mathrm{~d}, J=7.4 \mathrm{~Hz}, 3 \mathrm{H})$. Anal. Calcd. for $\mathrm{C}_{31} \mathrm{H}_{38} \mathrm{ClNO}_{8} \mathrm{~S}$ : C 60.04, H 6.18, N 2.26. Found: C 59.98, H 6.21, N 2.19.

(E)-2-(4-(2-(10ß-Dihydroartemisinoxy)ethoxy)phenyl)-N-(4-trifluoromethoxyphenyl)ethenesulfonamide (3c). Yellow solid (42\% yield); m.p.: $139-142{ }^{\circ} \mathrm{C}$; MS (ESI) $\mathrm{m} / \mathrm{z}: 692.1(\mathrm{M}+\mathrm{Na})^{+}$; IR (KBr) cm ${ }^{-1}: 3416.7$, 2924.6, 1604.1, 1510.7, 1346.0, 1258.8, 1224.3, 1027.9, 983.6, 838.8, 504.3; ${ }^{1} \mathrm{H}-\mathrm{NMR}(300 \mathrm{MHz}$, DMSO- $\left.d_{6}\right) \delta 10.06(\mathrm{br}, 1 \mathrm{H}), 7.56(\mathrm{~d}, J=8.5 \mathrm{~Hz}, 2 \mathrm{H}), 7.48(\mathrm{~d}, J=8.9 \mathrm{~Hz}, 2 \mathrm{H}), 7.37(\mathrm{~d}, J=8.5 \mathrm{~Hz}$, 2H), $7.19(\mathrm{~d}, J=15.3 \mathrm{~Hz}, 1 \mathrm{H}), 7.08(\mathrm{~d}, J=15.3 \mathrm{~Hz}, 1 \mathrm{H}), 6.79(\mathrm{~d}, J=8.6 \mathrm{~Hz}, 2 \mathrm{H}), 5.21(\mathrm{~s}, 1 \mathrm{H}), 4.60$ $(\mathrm{d}, J=3.3 \mathrm{~Hz}, 1 \mathrm{H}), 3.82(\mathrm{~m}, 2 \mathrm{H}), 3.76(\mathrm{~m}, 2 \mathrm{H}), 2.32(\mathrm{~m}, 1 \mathrm{H}), 2.15(\mathrm{~m}, 1 \mathrm{H}), 2.00(\mathrm{~m}, 1 \mathrm{H}), 1.76(\mathrm{~m}$, $1 \mathrm{H}), 1.46(\mathrm{~m}, 2 \mathrm{H}), 1.41(\mathrm{~m}, 1 \mathrm{H}), 1.26(\mathrm{~m}, 6 \mathrm{H}), 1.09(\mathrm{~m}, 2 \mathrm{H}), 0.87(\mathrm{~m}, 3 \mathrm{H}), 0.70(\mathrm{~d}, J=7.3 \mathrm{~Hz}, 3 \mathrm{H})$. Anal. Calcd. for $\mathrm{C}_{32} \mathrm{H}_{38} \mathrm{~F}_{3} \mathrm{NO}_{9} \mathrm{~S}$ : C 57.39, H 5.72, N 2.09. Found: C 57.41, H 5.68, N 2.11. 
(E)-2-(4-(2-(10ß-Dihydroartemisinoxy)ethoxy)phenyl)-N-(2-fluoro-5-methylphenyl)ethenesulfonamide (3d). Light yellow solid (36\% yield); m.p.: $138-140{ }^{\circ} \mathrm{C}$; MS (ESI) $m / z: 640.1(\mathrm{M}+\mathrm{Na})^{+}$; IR $(\mathrm{KBr}) \mathrm{cm}^{-1}$ : 3424.5, 2923.5, 1604.1, 1510.7, 1343.8, 1148.7, 1028.1, 984.6, 872.5, 601.1; ${ }^{1} \mathrm{H}-\mathrm{NMR}(300 \mathrm{MHz}$, DMSO-d $d_{6} \delta 10.06(\mathrm{br}, 1 \mathrm{H}), 7.56(\mathrm{~d}, J=8.5 \mathrm{~Hz}, 2 \mathrm{H}), 7.24(\mathrm{~m}, 2 \mathrm{H}), 7.18(\mathrm{~m}, 2 \mathrm{H}), 7.09$ (d, $J=15.3 \mathrm{~Hz}$, $1 \mathrm{H}), 6.81(\mathrm{~d}, J=8.6 \mathrm{~Hz}, 2 \mathrm{H}), 5.22(\mathrm{~s}, 1 \mathrm{H}), 4.59(\mathrm{~d}, J=3.2 \mathrm{~Hz}, 1 \mathrm{H}), 3.72(\mathrm{~m}, 4 \mathrm{H}), 2.26(\mathrm{~m}, 1 \mathrm{H}), 2.15$ $(\mathrm{s}, 3 \mathrm{H}), 2.10(\mathrm{~m}, 1 \mathrm{H}), 2.00(\mathrm{~m}, 1 \mathrm{H}), 1.77(\mathrm{~m}, 1 \mathrm{H}), 1.40(\mathrm{~m}, 3 \mathrm{H}), 1.28(\mathrm{~m}, 6 \mathrm{H}), 1.09(\mathrm{~m}, 2 \mathrm{H}), 0.87(\mathrm{~d}$, $J=5.9 \mathrm{~Hz}, 3 \mathrm{H}), 0.71(\mathrm{~d}, J=7.3 \mathrm{~Hz}, 3 \mathrm{H})$. Anal. Calcd. for $\mathrm{C}_{32} \mathrm{H}_{40} \mathrm{FNO}_{8} \mathrm{~S}: \mathrm{C}$ 62.22, $\mathrm{H}$ 6.53, N 2.27. Found: C 62.19, H 6.55, N 2.29.

(E)-2-(4-(2-(10ß-Dihydroartemisinoxy)ethoxy)phenyl)- $N$-(2-methylphenyl)ethenesulfonamide (3e). Light brown solid (26\% yield); m.p.: 136-138 ${ }^{\circ} \mathrm{C}$; MS (ESI) $m / z: 598.2(\mathrm{M}-\mathrm{H})^{-}$; IR (KBr) cm ${ }^{-1}: 3414.8$, 2923.1, 1604.2, 1514.7, 1342.5, 1146.2, 1027.5, 983.6, 872.4, 603.3; ${ }^{1} \mathrm{H}-\mathrm{NMR}$ (300 MHz, DMSO- $d_{6}$ ) $\delta 7.59(\mathrm{~d}, J=8.5 \mathrm{~Hz}, 2 \mathrm{H}), 7.28(\mathrm{~m}, 6 \mathrm{H}), 6.80(\mathrm{~d}, J=8.6 \mathrm{~Hz}, 2 \mathrm{H}), 5.15(\mathrm{~s}, 1 \mathrm{H}), 4.62(\mathrm{~d}, J=3.3 \mathrm{~Hz}, 1 \mathrm{H})$, $4.45(\mathrm{~d}, J=5.7 \mathrm{~Hz}, 1 \mathrm{H}), 3.82(\mathrm{~m}, 2 \mathrm{H}), 3.70(\mathrm{~m}, 2 \mathrm{H}), 2.35(\mathrm{~s}, 3 \mathrm{H}), 2.07-1.87(\mathrm{~m}, 1 \mathrm{H}), 1.75(\mathrm{~m}, 1 \mathrm{H}), 1.42$ $(\mathrm{m}, 2 \mathrm{H}), 1.26(\mathrm{~s}, 3 \mathrm{H}), 1.25(\mathrm{~m}, 4 \mathrm{H}), 1.06(\mathrm{t}, J=7.0 \mathrm{~Hz}, 2 \mathrm{H}), 0.86(\mathrm{~d}, J=5.9 \mathrm{~Hz}, 3 \mathrm{H}), 0.73$ (d, $J=7.3 \mathrm{~Hz}$, 3H). Anal. Calcd. for $\mathrm{C}_{32} \mathrm{H}_{41} \mathrm{NO}_{8} \mathrm{~S}$ : C 64.09, H 6.89, N 2.34. Found: C 64.13, H 6.81, N 2.39.

(E)-2-(4-(2-(10ß-Dihydroartemisinoxy)ethoxy)phenyl)-N-(4-chlorophenyl)ethenesulfonamide (3f). Light brown solid (44\% yield); m.p.: $138-141{ }^{\circ} \mathrm{C}$; MS (ESI) $m / z: 618.1(\mathrm{M}-\mathrm{H})^{-}$; IR (KBr) $\mathrm{cm}^{-1}: 3411.5$, 2925.1, 1601.5, 1490.3, 1343.2, 1149.3, 1054.2, 1027.0, 1007.0, 822.9, 760.8; ${ }^{1} \mathrm{H}-\mathrm{NMR}$ (300 MHz, DMSO- $\left.d_{6}\right) \delta 7.56(\mathrm{~d}, J=8.3 \mathrm{~Hz}, 1 \mathrm{H}), 7.43(\mathrm{~m}, 3 \mathrm{H}), 7.18(\mathrm{~m}, 2 \mathrm{H}), 7.01(\mathrm{~d}, J=8.8 \mathrm{~Hz}, 1 \mathrm{H}), 6.80(\mathrm{~d}$, $J=7.6 \mathrm{~Hz}, 1 \mathrm{H}), 6.67(\mathrm{~d}, J=7.0 \mathrm{~Hz}, 1 \mathrm{H}), 6.50(\mathrm{~d}, J=9.0 \mathrm{~Hz}, 1 \mathrm{H}), 5.17(\mathrm{~s}, 1 \mathrm{H}), 4.76(\mathrm{~d}, J=3.5 \mathrm{~Hz}$, $1 \mathrm{H}), 4.35(\mathrm{~m}, 2 \mathrm{H}), 3.82(\mathrm{~m}, 2 \mathrm{H}), 3.62(\mathrm{~m}, 2 \mathrm{H}), 2.05(\mathrm{~s}, 3 \mathrm{H}), 1.56(\mathrm{~m}, 2 \mathrm{H}), 1.35(\mathrm{~m}, 2 \mathrm{H}), 1.24(\mathrm{~s}, 3 \mathrm{H})$, $1.10(\mathrm{~m}, 3 \mathrm{H}), 0.97(\mathrm{~d}, J=6.0 \mathrm{~Hz}, 3 \mathrm{H}), 0.80(\mathrm{~d}, J=7.4 \mathrm{~Hz}, 3 \mathrm{H})$. Anal. Calcd. for $\mathrm{C}_{31} \mathrm{H}_{38} \mathrm{ClNO}_{8} \mathrm{~S}$ : C 60.04, H 6.18, N 2.26. Found: C 60.11, H 6.12, N 2.30.

(E)-2-(4-(2-(10ß-Dihydroartemisinoxy)ethoxy)phenyl)-N-(2-chlorophenyl)ethenesulfonamide (3g). Yellow solid (38\% yield); m.p.: $141-143{ }^{\circ} \mathrm{C}$; MS (ESI) $\mathrm{m} / z$ : $618.2(\mathrm{M}-\mathrm{H})^{-}$; IR (KBr) cm ${ }^{-1}$ : 3412.1, 2926.3, 1604.2, 1493.5, 1340.3, 1145.7, 1052.8, 1022.4, 828.5, 772.4; ${ }^{1} \mathrm{H}-\mathrm{NMR}\left(300 \mathrm{MHz}, \mathrm{DMSO}-d_{6}\right) \delta 7.65$ $(\mathrm{d}, J=8.2 \mathrm{~Hz}, 2 \mathrm{H}), 7.45(\mathrm{~m}, 2 \mathrm{H}), 7.28(\mathrm{~m}, 2 \mathrm{H}), 7.20(\mathrm{~d}, J=15.1 \mathrm{~Hz}, 1 \mathrm{H}), 7.04(\mathrm{~d}, J=15.1 \mathrm{~Hz}, 1 \mathrm{H})$, $6.81(\mathrm{~d}, J=8.3 \mathrm{~Hz}, 2 \mathrm{H}), 5.27(\mathrm{~s}, 1 \mathrm{H}), 4.62(\mathrm{~d}, J=3.2 \mathrm{~Hz}, 1 \mathrm{H}), 3.82(\mathrm{~m}, 2 \mathrm{H}), 3.76(\mathrm{~m}, 2 \mathrm{H}), 3.30$ $(\mathrm{m}, 2 \mathrm{H}), 2.81(\mathrm{~m}, 1 \mathrm{H}), 2.53(\mathrm{~m}, 1 \mathrm{H}), 2.37(\mathrm{~m}, 1 \mathrm{H}), 2.20(\mathrm{~m}, 1 \mathrm{H}), 2.00(\mathrm{~m}, 1 \mathrm{H}), 1.85(\mathrm{~m}, 1 \mathrm{H}), 1.51$ $(\mathrm{m}, 1 \mathrm{H}), 1.32(\mathrm{~m}, 2 \mathrm{H}), 1.27(\mathrm{~s}, 3 \mathrm{H}), 1.09(\mathrm{~s}, 1 \mathrm{H}), 0.85$ (d, $J=6.8 \mathrm{~Hz}, 3 \mathrm{H}), 0.79$ (d, $J=7.3 \mathrm{~Hz}, 3 \mathrm{H})$. Anal. Calcd. for $\mathrm{C}_{31} \mathrm{H}_{38} \mathrm{ClNO}_{8} \mathrm{~S}$ : C 60.04, H 6.18, N 2.26. Found: C 59.93, H 6.21, N 2.29.

(E)-2-(4-(2-(10ß-Dihydroartemisinoxy)ethoxy)phenyl)-N-(2,6-dichlorophenyl)ethenesulfonamide (3h). Brown solid (41\% yield); m.p.: $144-146{ }^{\circ} \mathrm{C}$; MS (ESI) m/z: $653.1(\mathrm{M}-\mathrm{H})^{-}$; IR (KBr) cm ${ }^{-1}: 3420.8$, 2922.6, 1602.6, 1508.2, 1348.2, 1147.1, 1027.8, 984.7, 874.3, 541.5; ${ }^{1} \mathrm{H}-\mathrm{NMR}$ (300 MHz, DMSO- $d_{6}$ ) $\delta 7.78(\mathrm{~d}, J=8.1 \mathrm{~Hz}, 2 \mathrm{H}), 7.28(\mathrm{~m}, 2 \mathrm{H}), 7.15(\mathrm{~d}, J=15.3 \mathrm{~Hz}, 1 \mathrm{H}), 6.97(\mathrm{~m}, 2 \mathrm{H}), 6.83(\mathrm{~d}, J=7.9 \mathrm{~Hz}$, 2H), $5.21(\mathrm{~s}, 1 \mathrm{H}), 4.62(\mathrm{~d}, J=3.3 \mathrm{~Hz}, 1 \mathrm{H}), 3.82(\mathrm{~m}, 4 \mathrm{H}), 2.31(\mathrm{~m}, 2 \mathrm{H}), 2.16(\mathrm{~s}, 2 \mathrm{H}), 2.12(\mathrm{~m}, 1 \mathrm{H})$, $1.98(\mathrm{~m}, 1 \mathrm{H}), 1.75(\mathrm{~m}, 2 \mathrm{H}), 1.39(\mathrm{~m}, 2 \mathrm{H}), 1.26(\mathrm{~m}, 6 \mathrm{H}), 1.07(\mathrm{~m}, 2 \mathrm{H}), 0.89(\mathrm{~d}, J=5.9 \mathrm{~Hz}, 3 \mathrm{H}), 0.78$ (d, $J=7.4 \mathrm{~Hz}, 3 \mathrm{H}$ ). Anal. Calcd. for $\mathrm{C}_{31} \mathrm{H}_{37} \mathrm{Cl}_{2} \mathrm{NO}_{8} \mathrm{~S}$ : C 56.88, H 5.70, N 2.14. Found: C 56.92, $\mathrm{H}$ 5.75, N 2.17 . 
(E)-N-(2-(10ß-Dihydroartemisinoxy)ethyl)-4((4-(2-(N-phenylsulfamoyl)vinyl)phenoxy)methyl)benzamide (6a). Light yellow solid (48\% yield); m.p.: $142-145^{\circ} \mathrm{C}$; MS (ESI) $\mathrm{m} / z: 717.1(\mathrm{M}-\mathrm{H})^{-}$; IR (KBr) cm ${ }^{-1}$ : 3413.1, 2924.1, 1604.2, 1513.9, 1336.6, 1146.1, 1020.8, 873.7, 801.7, 699.4, 603.3; ${ }^{1} \mathrm{H}-\mathrm{NMR}$ (300 MHz, DMSO-d $d_{6} \delta 8.49(\mathrm{br}, 1 \mathrm{H}), 7.85(\mathrm{~d}, J=8.1 \mathrm{~Hz}, 2 \mathrm{H}), 7.62(\mathrm{~m}, 2 \mathrm{H}), 7.50(\mathrm{~d}, J=8.0 \mathrm{~Hz}, 2 \mathrm{H}), 7.33(\mathrm{~d}$, $J=15.2 \mathrm{~Hz}, 1 \mathrm{H}), 7.24(\mathrm{t}, J=7.6 \mathrm{~Hz}, 2 \mathrm{H}), 7.17(\mathrm{~d}, J=8.1 \mathrm{~Hz}, 2 \mathrm{H}), 7.0(\mathrm{~m}, 4 \mathrm{H}), 5.26(\mathrm{~s}, 1 \mathrm{H}), 5.21$ (s, 2H), $4.69(\mathrm{~d}, J=3.2 \mathrm{~Hz}, 1 \mathrm{H}), 4.44(\mathrm{~d}, J=5.2 \mathrm{~Hz}, 1 \mathrm{H}), 4.39$ (t, $J=3.9 \mathrm{~Hz}, 2 \mathrm{H}), 3.82(\mathrm{~m}, 2 \mathrm{H}), 2.24(\mathrm{~m}$, 2H), $2.06(\mathrm{~m}, 3 \mathrm{H}), 1.67(\mathrm{~m}, 3 \mathrm{H}), 1.48(\mathrm{~m}, 2 \mathrm{H}), 1.26(\mathrm{~s}, 3 \mathrm{H}), 1.23(\mathrm{~s}, 1 \mathrm{H}), 0.81(\mathrm{~d}, J=7.4 \mathrm{~Hz}, 3 \mathrm{H})$, 0.68 (d, $J=5.6 \mathrm{~Hz}, 3 \mathrm{H})$. Anal. Calcd. for $\mathrm{C}_{39} \mathrm{H}_{46} \mathrm{~N}_{2} \mathrm{O}_{9} \mathrm{~S}$ : C 65.16, H 6.45, N 3.90. Found: C 65.09, H 6.43, N 3.96 .

(E)-N-(2-(10B-Dihydroartemisinoxy)ethyl)-4((4-(2-(N-(3-chlorophenyl) sulfamoyl) vinyl) phenoxy)methy l)benzamide (6b). Light yellow solid (45\% yield); m.p.: $146-149{ }^{\circ} \mathrm{C}$; MS (ESI) $m / z: 751.0$ (M-H) ${ }^{-}$; IR $(\mathrm{KBr}) \mathrm{cm}^{-1}$ : 3397.3, 2923.3, 1602.5, 1512.7, 1344.3, 1147.4, 1026.6, 983.7, 872.9, 791.7, 594.8; ${ }^{1} \mathrm{H}-\mathrm{NMR}\left(300 \mathrm{MHz}, \mathrm{DMSO}-d_{6}\right) \delta 8.40(\mathrm{br}, 1 \mathrm{H}), 7.74(\mathrm{~d}, J=8.2 \mathrm{~Hz}, 2 \mathrm{H}), 7.60(\mathrm{~d}, J=8.5 \mathrm{~Hz}, 2 \mathrm{H}), 7.50$ $(\mathrm{d}, J=13.1 \mathrm{~Hz}, 2 \mathrm{H}), 7.37(\mathrm{~d}, J=8.2 \mathrm{~Hz}, 2 \mathrm{H}), 7.32(\mathrm{~d}, J=4.6 \mathrm{~Hz}, 2 \mathrm{H}), 7.26(\mathrm{~d}, J=8.1 \mathrm{~Hz}, 2 \mathrm{H}), 6.82$ $(\mathrm{d}, J=8.2 \mathrm{~Hz}, 2 \mathrm{H}), 5.25(\mathrm{~s}, 1 \mathrm{H}), 4.92(\mathrm{~d}, J=13.4 \mathrm{~Hz}, 2 \mathrm{H}), 4.68(\mathrm{~d}, J=3.0 \mathrm{~Hz}, 1 \mathrm{H}), 3.82(\mathrm{~m}, 2 \mathrm{H})$, $3.53(\mathrm{~m}, 2 \mathrm{H}), 2.34(\mathrm{~m}, 1 \mathrm{H}), 2.12(\mathrm{~m}, 2 \mathrm{H}), 2.00(\mathrm{~m}, 2 \mathrm{H}), 1.66(\mathrm{~m}, 2 \mathrm{H}), 1.49(\mathrm{~m}, 2 \mathrm{H}), 1.26(\mathrm{~m}, 6 \mathrm{H}), 0.80$ $(\mathrm{d}, J=7.2 \mathrm{~Hz}, 3 \mathrm{H}), 0.65(\mathrm{~d}, J=5.7 \mathrm{~Hz}, 3 \mathrm{H})$. Anal. Calcd. for $\mathrm{C}_{39} \mathrm{H}_{45} \mathrm{ClN}_{2} \mathrm{O}_{9} \mathrm{~S}: \mathrm{C} 62.18, \mathrm{H} 6.02, \mathrm{~N}$ 3.72. Found: C 62.23, H 6.18, N 3.68 .

(E)-N-(2-(10ß-Dihydroartemisinoxy)ethyl)-4((4-(2-(N-(4-trifluoromethoxyphenyl)sulfamoyl)vinyl)phen oxy)methyl)benzamide (6c). Yellow solid (43\% yield); m.p.: $149-151{ }^{\circ} \mathrm{C}$; MS (ESI) $\mathrm{m} / \mathrm{z}: 801.2(\mathrm{M}-\mathrm{H})^{-}$; IR (KBr) cm ${ }^{-1}: 3396.9,2924.0,1603.0,1507.9,1346.4,1360.2,1146.2,1025.4,870.5,801.6,593.1$; ${ }^{1} \mathrm{H}-\mathrm{NMR}\left(300 \mathrm{MHz}, \mathrm{DMSO}-d_{6}\right) \delta 8.38(\mathrm{br}, 1 \mathrm{H}), 7.74(\mathrm{~d}, J=8.2 \mathrm{~Hz}, 2 \mathrm{H}), 7.60(\mathrm{~d}, J=8.5 \mathrm{~Hz}, 2 \mathrm{H})$, $7.47(\mathrm{~d}, J=9.0 \mathrm{~Hz}, 2 \mathrm{H}), 7.37(\mathrm{~d}, J=8.0 \mathrm{~Hz}, 2 \mathrm{H}), 7.34(\mathrm{~m}, 4 \mathrm{H}), 6.82(\mathrm{~d}, J=8.2 \mathrm{~Hz}, 2 \mathrm{H}), 5.25$ (s, $1 \mathrm{H}), 4.88(\mathrm{~s}, 2 \mathrm{H}), 4.68(\mathrm{~d}, J=3.2 \mathrm{~Hz}, 1 \mathrm{H}), 4.45(\mathrm{~m}, 1 \mathrm{H}), 4.35(\mathrm{~m}, 1 \mathrm{H}), 3.82(\mathrm{~s}, 2 \mathrm{H}), 3.62(\mathrm{~m}, 1 \mathrm{H})$, $2.35(\mathrm{~m}, 1 \mathrm{H}), 2.11(\mathrm{~m}, 1 \mathrm{H}), 1.96(\mathrm{~m}, 1 \mathrm{H}), 1.65(\mathrm{~m}, 3 \mathrm{H}), 1.51(\mathrm{~m}, 1 \mathrm{H}), 1.25(\mathrm{~m}, 7 \mathrm{H}), 0.79(\mathrm{~d}, J=7.2 \mathrm{~Hz}$, $3 \mathrm{H}), 0.65(\mathrm{~d}, J=5.8 \mathrm{~Hz}, 3 \mathrm{H})$. Anal. Calcd. for $\mathrm{C}_{40} \mathrm{H}_{45} \mathrm{~F}_{3} \mathrm{~N}_{2} \mathrm{O}_{10} \mathrm{~S}: \mathrm{C} 59.84, \mathrm{H} \mathrm{5.65,} \mathrm{N} \mathrm{3.49}$. Found: C 59.93, H 5.69, N 3.52 .

(E)-N-(2-(10ß-Dihydroartemisinoxy)ethyl)-4((4-(2-(N-(2-fluoro-5-methylphenyl)sulfamoyl)vinyl)pheno xy)methyl)benzamide (6d) Light yellow solid (35\% yield); m.p.: $135-137{ }^{\circ} \mathrm{C}$; MS (ESI) $m / z: 749.2$ (M-H) ; IR (KBr) cm ${ }^{-1}$ : 3412.2, 2924.6, 1603.9, 1509.1, 1343.9, 1146.1, 1025.8, 984.1, 872.7, 843.9, 597.9; ${ }^{1} \mathrm{H}-\mathrm{NMR}\left(300 \mathrm{MHz}, \mathrm{DMSO}-d_{6}\right) \delta 8.40(\mathrm{br}, 1 \mathrm{H}), 7.74(\mathrm{~d}, J=8.1 \mathrm{~Hz}, 2 \mathrm{H}), 7.60(\mathrm{~d}, J=8.4 \mathrm{~Hz}$, 2H), 7.41(d, $J=8.2 \mathrm{~Hz}, 2 \mathrm{H}), 7.28(\mathrm{~s}, 1 \mathrm{H}), 7.20(\mathrm{~m}, 2 \mathrm{H}), 7.13(\mathrm{~m}, 2 \mathrm{H}), 6.83(\mathrm{~d}, J=8.1 \mathrm{~Hz}, 2 \mathrm{H}), 5.26$ $(\mathrm{s}, 1 \mathrm{H}), 4.78(\mathrm{~s}, 2 \mathrm{H}), 4.69(\mathrm{~d}, J=3.3 \mathrm{~Hz}, 1 \mathrm{H}), 4.46(\mathrm{~d}, J=3.5 \mathrm{~Hz}, 1 \mathrm{H}), 4.39(\mathrm{~m}, 1 \mathrm{H}), 3.82(\mathrm{~m}, 2 \mathrm{H})$, $3.52(\mathrm{~m}, 2 \mathrm{H}), 2.34(\mathrm{~m}, 1 \mathrm{H}), 2.19(\mathrm{~s}, 3 \mathrm{H}), 2.10(\mathrm{~m}, 1 \mathrm{H}), 1.94(\mathrm{~m}, 1 \mathrm{H}), 1.66(\mathrm{~m}, 2 \mathrm{H}), 1.52(\mathrm{~m}, 1 \mathrm{H}), 1.38$ $(\mathrm{s}, 1 \mathrm{H}), 1.25(\mathrm{~m}, 6 \mathrm{H}), 0.80(\mathrm{~d}, J=7.3 \mathrm{~Hz}, 3 \mathrm{H}), 0.66(\mathrm{~d}, J=5.6 \mathrm{~Hz}, 3 \mathrm{H})$. Anal. Calcd. for $\mathrm{C}_{40} \mathrm{H}_{47} \mathrm{FN}_{2} \mathrm{O}_{9} \mathrm{~S}$ : C 63.98, H 6.31, N 3.73. Found: C 64.02, H 6.37, N 3.68.

(E)-N-(2-(10ß-Dihydroartemisinoxy)ethyl)-4((4-(2-(N-(2-methylphenyl)sulfamoyl) vinyl)phenoxy)methyl) benzamide (6e) Light yellow solid (40\% yield); m.p.: $143-145{ }^{\circ} \mathrm{C}$; MS (ESI) m/z: 731.2 (M-H) ${ }^{-}$; IR $(\mathrm{KBr}) \mathrm{cm}^{-1}$ : 3397.2, 2923.2, 1603.4, 1510.1, 1341.8, 1143.7, 1027.5, 984.2, 874.6, 800.3, 594.8; 
${ }^{1} \mathrm{H}-\mathrm{NMR}\left(300 \mathrm{MHz}, \mathrm{DMSO}-d_{6}\right) \delta 8.39(\mathrm{~s}, 1 \mathrm{H}), 7.71(\mathrm{~d}, J=8.1 \mathrm{~Hz}, 2 \mathrm{H}), 7.61(\mathrm{~m}, 4 \mathrm{H}), 7.34(\mathrm{~m}, 4 \mathrm{H})$, $7.15(\mathrm{~d}, J=8.2 \mathrm{~Hz}, 2 \mathrm{H}), 6.83(\mathrm{~d}, J=8.2 \mathrm{~Hz}, 2 \mathrm{H}), 5.29(\mathrm{~s}, 1 \mathrm{H}), 4.87(\mathrm{~m}, 1 \mathrm{H}), 4.69(\mathrm{~m}, 2 \mathrm{H}), 3.83(\mathrm{~m}$, 2H), $3.47(\mathrm{~m}, 2 \mathrm{H}), 2.40(\mathrm{~m}, 2 \mathrm{H}), 2.31(\mathrm{~s}, 1 \mathrm{H}), 2.15(\mathrm{~m}, 1 \mathrm{H}), 2.07(\mathrm{~s}, 3 \mathrm{H}), 1.95(\mathrm{~m}, 2 \mathrm{H}), 1.70(\mathrm{~m}, 2 \mathrm{H})$, $1.51(\mathrm{~m}, 1 \mathrm{H}), 1.27(\mathrm{~m}, 4 \mathrm{H}), 1.04(\mathrm{~m}, 2 \mathrm{H}), 0.80(\mathrm{~d}, J=7.3 \mathrm{~Hz}, 3 \mathrm{H}), 0.72(\mathrm{~d}, J=4.7 \mathrm{~Hz}, 3 \mathrm{H})$. Anal. Calcd. for $\mathrm{C}_{40} \mathrm{H}_{48} \mathrm{~N}_{2} \mathrm{O}_{9} \mathrm{~S}$ : C 65.55, H 6.60, N 3.82. Found: C 65.48, H 6.57, N 3.85.

(E)-N-(2-(10ß-Dihydroartemisinoxy)ethyl)-4((4-(2-(N-(4-chlorophenyl)sulfamoyl)vinyl)phenoxy)methyl) benzamide (6f). Yellow solid (39\% yield); m.p.: $138-141{ }^{\circ} \mathrm{C}$; MS (ESI) $m / z$ : $751.1(\mathrm{M}-\mathrm{H})^{-}$; IR (KBr) $\mathrm{cm}^{-1}$ : 3397.1, 2923.1, 1603.4, 1509.9, 1345.8, 1146.5, 1026.2, 982.5, 871.4, 800.5, 594.3; ${ }^{1} \mathrm{H}-\mathrm{NMR}$ (300 MHz, DMSO- $\left.d_{6}\right) \delta 8.39$ (br, 1H), $7.72(\mathrm{~d}, J=8.2 \mathrm{~Hz}, 2 \mathrm{H}), 7.59$ (d, $\left.J=8.5 \mathrm{~Hz}, 2 \mathrm{H}\right), 7.48(\mathrm{~d}$, $J=13.1 \mathrm{~Hz}, 2 \mathrm{H}), 7.32(\mathrm{~d}, J=8.2 \mathrm{~Hz}, 2 \mathrm{H}), 7.28(\mathrm{~d}, J=4.6 \mathrm{~Hz}, 2 \mathrm{H}), 7.17(\mathrm{~d}, J=8.1 \mathrm{~Hz}, 2 \mathrm{H}), 6.80(\mathrm{~d}$, $J=8.2 \mathrm{~Hz}, 2 \mathrm{H}), 5.24(\mathrm{~s}, 1 \mathrm{H}), 4.83(\mathrm{~s}, 2 \mathrm{H}), 4.62(\mathrm{~d}, J=3.2 \mathrm{~Hz}, 1 \mathrm{H}), 4.41(\mathrm{~m}, 1 \mathrm{H}), 4.30(\mathrm{~m}, 1 \mathrm{H}), 3.81$ $(\mathrm{s}, 2 \mathrm{H}), 3.60(\mathrm{~m}, 1 \mathrm{H}), 2.33(\mathrm{~m}, 1 \mathrm{H}), 2.08(\mathrm{~m}, 1 \mathrm{H}), 1.93(\mathrm{~m}, 1 \mathrm{H}), 1.61(\mathrm{~m}, 3 \mathrm{H}), 1.47(\mathrm{~m}, 2 \mathrm{H}), 1.26(\mathrm{~m}$, $6 \mathrm{H}), 0.78(\mathrm{~d}, J=7.2 \mathrm{~Hz}, 3 \mathrm{H}), 0.64(\mathrm{~d}, J=5.8 \mathrm{~Hz}, 3 \mathrm{H})$. Anal. Calcd. for $\mathrm{C}_{39} \mathrm{H}_{45} \mathrm{ClN}_{2} \mathrm{O}_{9} \mathrm{~S}: \mathrm{C} 62.18, \mathrm{H}$ 6.02, N 3.72. Found: C 62.23, H 5.98, N 3.76.

(E)-N-(2-(10ß-Dihydroartemisinoxy)ethyl)-4((4-(2-(N-(2-chlorophenyl)sulfamoyl)vinyl)phenoxy)methyl) benzamide (6g). Light yellow solid (38\% yield); m.p.: $147-150{ }^{\circ} \mathrm{C}$; MS (ESI) $m / z$ : $775.2(\mathrm{M}+\mathrm{Na})^{+}$; IR (KBr) $\mathrm{cm}^{-1}: 3394.1,2925.3,1605.5,1499.1,1339.3,1144.8,1028.8,979.5,881.7,806.7$, 598.2; ${ }^{1} \mathrm{H}-\mathrm{NMR}\left(300 \mathrm{MHz}, \mathrm{DMSO}-d_{6}\right) \delta 7.59(\mathrm{~m}, 2 \mathrm{H}), 7.40(\mathrm{~d}, J=8.6 \mathrm{~Hz}, 4 \mathrm{H}), 7.32(\mathrm{~m}, 3 \mathrm{H}), 6.94(\mathrm{~s}, 2 \mathrm{H})$, $6.79(\mathrm{~m}, 3 \mathrm{H}), 5.62(\mathrm{~s}, 1 \mathrm{H}), 5.35(\mathrm{~d}, J=10.3 \mathrm{~Hz}, 1 \mathrm{H}), 4.80(\mathrm{~s}, 2 \mathrm{H}), 4.68(\mathrm{~d}, J=3.1 \mathrm{~Hz}, 1 \mathrm{H}), 3.81(\mathrm{~m}$, 2H), $3.45(\mathrm{~m}, 2 \mathrm{H}), 2.18(\mathrm{~m}, 1 \mathrm{H}), 2.05(\mathrm{~m}, 2 \mathrm{H}), 1.94(\mathrm{~m}, 2 \mathrm{H}), 1.63(\mathrm{~m}, 2 \mathrm{H}), 1.52(\mathrm{~m}, 2 \mathrm{H}), 1.33(\mathrm{~s}, 3 \mathrm{H})$, $0.98(\mathrm{~m}, 2 \mathrm{H}), 0.83(\mathrm{~d}, J=7.4 \mathrm{~Hz}, 3 \mathrm{H}), 0.71(\mathrm{~d}, J=5.7 \mathrm{~Hz}, 3 \mathrm{H})$. Anal. Calcd. for $\mathrm{C}_{39} \mathrm{H}_{45} \mathrm{ClN}_{2} \mathrm{O}_{9} \mathrm{~S}$ : C 62.18, H 6.02, N 3.72. Found: C 62.12, H 5.97, N 3.79.

(E)-N-(2-(10ß-Dihydroartemisinoxy)ethyl)-4((4-(2-(N-(2,6-dichlorophenyl)sulfamoyl)vinyl)phenoxy)m ethyl)benzamide (6h). Light yellow solid (40\% yield); m.p.: $151-153{ }^{\circ} \mathrm{C}$; MS (ESI) $\mathrm{m} / \mathrm{z}: 784.9$ (M-H) IR (KBr) cm ${ }^{-1}: 3420.8,2922.6,1602.6,1508.2,1348.2,1147.1,1027.8,984.7,874.3,541.5 ;{ }^{1} \mathrm{H}-\mathrm{NMR}$ $\left(300 \mathrm{MHz}, \mathrm{DMSO}-d_{6}\right) \delta 8.40(\mathrm{br}, 1 \mathrm{H}), 7.75(\mathrm{~d}, J=8.1 \mathrm{~Hz}, 1 \mathrm{H}), 7.62(\mathrm{~d}, J=8.3 \mathrm{~Hz}, 2 \mathrm{H}), 7.59(\mathrm{~m}, 4 \mathrm{H})$, $7.28(\mathrm{~m}, 4 \mathrm{H}), 6.84(\mathrm{~d}, J=7.5 \mathrm{~Hz}, 2 \mathrm{H}), 5.26(\mathrm{~s}, 1 \mathrm{H}), 4.80(\mathrm{~s}, 2 \mathrm{H}), 4.69$ (d, $J=3.3 \mathrm{~Hz}, 1 \mathrm{H}), 3.85(\mathrm{~m}$, 2H), $3.59(\mathrm{~m}, 2 \mathrm{H}), 2.35(\mathrm{~m}, 1 \mathrm{H}), 2.13(\mathrm{~m}, 1 \mathrm{H}), 1.97(\mathrm{~m}, 2 \mathrm{H}), 1.67(\mathrm{~m}, 3 \mathrm{H}), 1.52(\mathrm{~m}, 2 \mathrm{H}), 1.27(\mathrm{~s}, 3 \mathrm{H})$, $1.24(\mathrm{~s}, 2 \mathrm{H}), 1.04(\mathrm{~m}, 1 \mathrm{H}), 0.81(\mathrm{~d}, J=7.4 \mathrm{~Hz}, 3 \mathrm{H}), 0.69(\mathrm{~d}, J=4.5 \mathrm{~Hz}, 3 \mathrm{H})$. Anal. Calcd. for $\mathrm{C}_{39} \mathrm{H}_{44} \mathrm{Cl}_{2} \mathrm{~N}_{2} \mathrm{O}_{9} \mathrm{~S}$ : C 59.46, H 5.63, N 3.56. Found: C 59.42, H 5.59, N 3.50.

(E)-N-(2-(10ß-Dihydroartemisinoxy)ethyl)-4((4-(2-(N-(3-methoxyphenyl)sulfamoyl)vinyl)phenoxy)met hyl)benzamide (6i). Light yellow solid (48\% yield); m.p.: $144-145{ }^{\circ} \mathrm{C}$; MS (ESI) $\mathrm{m} / z$ : $747.2(\mathrm{M}-\mathrm{H})^{-}$; IR (KBr) $\mathrm{cm}^{-1}:$ 3392.7, 2923.7, 1603.2, 1512.6, 1340.0, 1142.2, 1025.9, 982.8, 871.7, 840.7, 596.3; ${ }^{1} \mathrm{H}-\mathrm{NMR}\left(300 \mathrm{MHz}, \mathrm{DMSO}-d_{6}\right) \delta 8.40(\mathrm{br}, 1 \mathrm{H}), 7.74(\mathrm{~d}, J=8.2 \mathrm{~Hz}, 2 \mathrm{H}), 7.60(\mathrm{~d}, J=8.5 \mathrm{~Hz}, 2 \mathrm{H})$, $7.50(\mathrm{~s}, 1 \mathrm{H}), 7.43(\mathrm{~s}, 1 \mathrm{H}), 7.37$ (d, $J=8.2 \mathrm{~Hz}, 2 \mathrm{H}), 7.32(\mathrm{~d}, J=4.6 \mathrm{~Hz}, 2 \mathrm{H}), 7.26(\mathrm{~d}, J=8.1 \mathrm{~Hz}, 2 \mathrm{H})$, $6.82(\mathrm{~d}, J=8.6 \mathrm{~Hz}, 2 \mathrm{H}), 5.25(\mathrm{~s}, 1 \mathrm{H}), 4.92(\mathrm{~d}, J=5.4 \mathrm{~Hz}, 2 \mathrm{H}), 4.68(\mathrm{~m}, 1 \mathrm{H}), 3.95(\mathrm{~s}, 3 \mathrm{H}), 3.82(\mathrm{~m}$, $2 \mathrm{H}), 3.51(\mathrm{~m}, 2 \mathrm{H}), 2.34(\mathrm{~m}, 2 \mathrm{H}), 2.12(\mathrm{~m}, 2 \mathrm{H}), 2.00(\mathrm{~m}, 2 \mathrm{H}), 1.66(\mathrm{~m}, 2 \mathrm{H}), 1.49(\mathrm{~m}, 1 \mathrm{H}), 1.26(\mathrm{~s}, 3 \mathrm{H})$, $1.21(\mathrm{~m}, 3 \mathrm{H}), 0.81(\mathrm{~d}, J=7.3 \mathrm{~Hz}, 3 \mathrm{H}), 0.69(\mathrm{~d}, J=5.2 \mathrm{~Hz}, 3 \mathrm{H})$. Anal. Calcd. for $\mathrm{C}_{40} \mathrm{H}_{48} \mathrm{~N}_{2} \mathrm{O}_{10} \mathrm{~S}$ : C 64.15, H 6.46, N 3.74. Found: C 64.09, H 6.41, N 3.67. 
(E)-N-(2-(10B-Dihydroartemisinoxy)ethyl)-4((4-(2-(N-(3-trifluoromethyl-4fluorophenyl)sulfamoyl)vinyl) phenoxy)methyl)benzamide (6j). Yellow solid (32\% yield); m.p.: $152-154{ }^{\circ} \mathrm{C}$; MS (ESI) $\mathrm{m} / z: 803.2$ $(\mathrm{M}-\mathrm{H})^{-}$; IR (KBr) cm ${ }^{-1}: 3401.8,2924.7,1602.3,1503.7,1328.9,1145.3,1026.0,983.9,845.8,646.6$, 542.5; ${ }^{1} \mathrm{H}-\mathrm{NMR}\left(300 \mathrm{MHz}, \mathrm{DMSO}-d_{6}\right) \delta 8.40(\mathrm{br}, 1 \mathrm{H}), 7.81(\mathrm{~m}, 4 \mathrm{H}), 7.63(\mathrm{~m}, 3 \mathrm{H}), 7.47(\mathrm{~d}, J=15.6$ $\mathrm{Hz}, 1 \mathrm{H}), 7.37$ (t, $J=8.4 \mathrm{~Hz}, 2 \mathrm{H}), 7.27(\mathrm{~d}, J=15.6 \mathrm{~Hz}, 1 \mathrm{H}), 6.82(\mathrm{~d}, J=8.6 \mathrm{~Hz}, 2 \mathrm{H}), 5.24(\mathrm{~s}, 1 \mathrm{H}), 4.98$ $(\mathrm{s}, 1 \mathrm{H}), 4.93(\mathrm{~s}, 2 \mathrm{H}), 4.68(\mathrm{~d}, J=3.1 \mathrm{~Hz}, 1 \mathrm{H}), 3.83(\mathrm{~m}, 2 \mathrm{H}), 3.51(\mathrm{~m}, 2 \mathrm{H}), 2.34(\mathrm{~m}, 1 \mathrm{H}), 2.16(\mathrm{~m}, 2 \mathrm{H})$, $1.94(\mathrm{~m}, 1 \mathrm{H}), 1.65(\mathrm{~m}, 2 \mathrm{H}), 1.49(\mathrm{~m}, 1 \mathrm{H}), 1.26(\mathrm{~s}, 4 \mathrm{H}), 1.14(\mathrm{~m}, 2 \mathrm{H}), 1.05(\mathrm{~m}, 1 \mathrm{H}), 0.79(\mathrm{~d}, J=7.3 \mathrm{~Hz}$, $3 \mathrm{H}), 0.60$ (d, $J=6.0 \mathrm{~Hz}, 3 \mathrm{H})$. Anal. Calcd. for $\mathrm{C}_{40} \mathrm{H}_{44} \mathrm{~F}_{4} \mathrm{~N}_{2} \mathrm{O}_{9} \mathrm{~S}$ : C 59.69, H 5.51, N 3.48. Found: C 59.74, H 5.46, N 3.41 .

\subsection{Evaluation of Biological Activity}

The cytotoxic activities of compounds $\mathbf{3 a}-\mathbf{h}$ and $\mathbf{6 a}-\mathbf{j}$ were evaluated with the HT-29, MDA-MB-231, U87MG, H460, A549, HL-60 cancer cell lines and one normal cell line, WI-38, by the standard MTT assay in vitro [20], with DHA as the positive control. The cell lines were cultured in minimum essential medium (MEM) supplement with 10\% fetal bovine serum (FBS). Approximately $4 \times 10^{3}$ cells, suspended in MEM medium, were plated on to each well of a 96-well plate and incubated in $5 \% \mathrm{CO}_{2}$ at $37{ }^{\circ} \mathrm{C}$ for $24 \mathrm{~h}$. The test compounds at indicated final concentrations were added to the culture medium and the cell cultures were continued for $72 \mathrm{~h}$. Fresh MTT was added to each well at a terminal concentration of $5 \mu \mathrm{g} / \mathrm{mL}$ and incubated with cells at $37^{\circ} \mathrm{C}$ for $4 \mathrm{~h}$. The formazan crystals were dissolved in $100 \mu \mathrm{L}$ DMSO each well, and the absorbency at $492 \mathrm{~nm}$ (for absorbance of MTT formazan) and $630 \mathrm{~nm}$ (for the reference wavelength) was measured with the ELISA reader. All of the compounds were tested twice in each of the cell lines. The results expressed as $\mathrm{IC}_{50}$ (inhibitory concentration $50 \%$ ) were the averages of two determinations and calculated using the Bacus Laboratories Incorporated Slide Scanner (Bliss) software.

\section{Conclusions}

In summary, two series of 10 -substituted dihydroartemisinin derivatives containing $N$-aryl phenylethenesulfonamide groups were prepared. Through anti-tumor activity screening the following conclusion can be reached about their structure-activity relationships: (a) all the target compounds were more potent than DHA and displayed less toxicity against the normal cell line WI-38, indicating that the presence of $N$-phenyl phenylethenesulfonamides moiety significantly enhanced their antitumor activities against the six cancer cell lines; (b) most compounds displayed good selectivity for inhibition of MDA-MB-231, HT-29, and especially the HL-60 cancer cell lines; (c) the substituent on the N-phenyl ring might play an important role in the tested compounds' activities. The introduction of halogen, especially trifluoromethoxy group at the 4-position of the $N$-phenyl group could enhance the cytotoxic activities, while methyl or methoxy groups decreased the potency. 


\section{References}

1. Lai, H.; Singh, N.P. Oral artemisinin prevents and delays the development of 7,12-dimethylbenz[a]anthracene (DMBA)-induced breast cancer in the rat. Cancer Lett. 2006, $231,43-48$.

2. Efferth, T.; Dunstan, H.; Sauerbrey, A.; Miyachi, H.; Chitambar, CR. The anti-malarial artesunate is also active against cancer. Int. J. Oncol. 2001, 18, 767-773.

3. Gordi, T.; Lepist, E.I. Artemisinin derivatives: Toxic for laboratory animals, safe for humans. Toxicol. Lett. 2004, 147, 99-107.

4. Dondorp, A.M.; Nosten, F.; Yi, P.; Das, D.; Phyo, A.P.; Tarning, J.; Lwin, K.M.; Ariey, F.; Hanpithakpong, W.; Lee, S.J.; et al. Artemisinin resistance in Plasmodium falciparum malaria. N. Engl. J. Med. 2009, 361, 455-467.

5. Wiesner, S.; Helfer, E.; Didry, D.; Ducouret, G.; Lafuma, F.; Carlier, M.F.; Pantaloni, D. A biomimetic motility assay provides insight into the mechanism of actin-based motility. J. Cell Biol. 2003, 160, 387-398.

6. Singh, N.P.; Lai, H.C. Artemisinin induces apoptosis in human cancer cells. Anticancer Res. 2004, 24, 2277-2280.

7. Li, Y.; Wu, J.M.; Shan, F.; Wu, G.S.; Ding, J.; Xiao, D.; Han, J.X.; Atassi, G.; Leonce, S.; Caignard, D.H.; et al. Synthesis and cytotoxicity of dihydroartemisinin ethers containing cyanoarylmethyl group. Bioorg. Med. Chem. 2003, 11, 977-984.

8. Chaturvedi, D.; Goswami, A.; Saikia, P.P.; Barua, N.C.; Rao, P.G. Artemisinin and its derivatives: A novel class of anti-malarial and anti-cancer agents. Chem. Soc. Rev. 2010, 39, 435-454.

9. Xie, L.; Zhao, Y.; Zhai, X.; Li, P.; Liu, C.; Li Y.; Gong, P. The application of tandem aza-Wittig reaction to synthesize artemisinin-guanidine hybrids and their antitumor activity. Arch. Pharm. 2011, 344, 631-638.

10. Xie, L.; Zhai, X.; Ren, L.; Meng, H.; Liu, C.; Zhu, W.; Zhao. Y. Design, synthesis and antitumor activity of novel artemisinin derivatives using hybrid approach, Chem. Pharm. Bull. (Tokyo) 2011, 59, 984-990.

11. Saikia, B.; Saikia, P.P.; Goswami, A.; Barua N.C.; Saxena, A.K.; Suri, N. Synthesis of a Novel Series of 1,2,3-Triazole-Containing Artemisinin Dimers with Potent Anticancer Activity Involving Huisgen 1,3-Dipolar Cycloaddition Reaction. Synthesis 2011, 19, 3173-3179.

12. Yang, X.; Wang, W.; Tan, J.; Song, D.; Li, M.; Liu, D.; Jing, Y.; Zhao, L. Synthesis of a series of novel dihydroartemisinin derivatives containing a substituted chalcone with greater cytotoxic effects in leukemia cells. Bioorg. Med. Chem. Lett. 2009, 19, 4385-4388.

13. Michael, J.; Amy, E.M.; Paul, A.S.; Louise, L.P.; Rick, C.; Kevin, P.; Miriam, E.K.; Ivo, P.; Stephen, A.W.; Jill, D.; et al. Antitumour and antimalarial activity of artemisinin-acridine hybrids. Bioorg. Med. Chem. Lett. 2009, 19, 2033-2037.

14. Pérez, J.M.; López-Solera, I.; Montero, E.I.; Brana, M.F.; Alonso, C.; Robinson, S.P.; Navarro-Ranninger, C. Combined effect of platination and intercalation upon DNA binding of novel cytotoxic Pt-bis(naphthalimide) complexes. J. Med. Chem. 1999, 42, 5482-5486.

15. Meunier, B. Hybrid molecules with a dual mode of action: Dream or reality? Acc. Chem. Res. 2008, 41, 69-77. 
16. Onconova Therapeutics; Temple University. Cancer Chemotherapy. ON-24160. Drug Data Rep. 2008, 30, 636.

17. Reddy, M.V.R.; Cosenza, S.C.; Pallela, V.R.; Natala, S.R.; Mallireddigari, M.R.; Maniar, M.; Iqbal, N.M.; Reddy, E.P. Design, synthesis and biological evaluation of novel, orally available tubulin depolymerizing (E) N-aryl-2-arylethenesulfonamide compounds. Proc. Am. Assoc. Cancer Res. 2008, 49, Abst. 1410.

18. Yu, P.L.; Chen, Y.X.; Li, Y.; Ji, R.Y.; Synthesis of qinghaosu derivatives Containing halogen, nitrogen and sufur atoms. Acta Pharm. Sin. 1985, 20, 357-365.

19. Haynes, R.K.; Ho, W.Y.; Chan, H.W.; Fugmann, B.; Stetter, J.; Vivas, L.; Peters, W.; Robinson, B.L. Highly Antimalaria-Active Artemisinin Derivatives: Biological Activity Does Not Correlate with Chemical Reactivity. Angew. Chem. Int. Ed. Engl. 2004, 43, 1381-1385.

20. Xu, S.Y.; Xu, S.Y.; Bian, R.L.; Chen, X. Method of Pharmacology; Public Health Publishing House: Beijing, China, 2002; pp. 1784-1786.

Sample Availability: Samples of the compounds $\mathbf{3 a}-\mathbf{h}$ and $\mathbf{6 a}-\mathbf{j}$ are available from the authors.

(C) 2013 by the authors; licensee MDPI, Basel, Switzerland. This article is an open access article distributed under the terms and conditions of the Creative Commons Attribution license (http://creativecommons.org/licenses/by/3.0/). 